\title{
La impronta andina en la poesía de César Vallejo
}

\section{Gustavo Lespada}

Universidad de Buenos Aires, Instituto de Literatura Hispanoamericana, Argentina

\begin{abstract}
Resumen
Si en Los heraldos negros se manifiesta la rebeldía temática, sobre todo ante un mundo abandonado por Dios, y si en Trilce predomina la rebelión categórica contra el estatuto del lenguaje y el universo simbólico, Poemas humanos y España, aparta de mí este cáliz componen la síntesis perfecta de la crítica social y humana con las transgresiones formales más audaces. El proyecto poético de César Vallejo, que comienza a perfilarse desde sus primeros versos, contiene-además de terminología e imaginario quechua- registros de la oralidad y numerosos elementos identitarios propios de la cosmovisión incaica de cuya ascendencia se enorgullece. Las concepciones comunitarias del Ayllu incaico se encuentran cifradas en su cristianismo sincrético en Los heraldos negros, para luego manifestarse en Trilce, en franca oposición a la hostilidad y las relaciones contractuales o mercantilistas de la ciudad moderna. Identificar y estudiar esta persistente identidad cultural a partir de distintas entradas a su obra poética es el objetivo de este trabajo.
\end{abstract}

PALABRAS CLAVE: Ayllu, poesía, comunidad, lenguaje, oralidad

\section{The Andean imprint in the poetry of César Vallejo}

\begin{abstract}
If in The Black Messengers the thematic rebellion manifests itself, especially before a world abandoned by God, and if in Trilce the categorical rebellion predominates against the statute of language and the symbolic universe, Human Poems and Spain, Take This Chalice from Me make up the perfect synthesis of social and human criticism with the boldest formal transgressions. The poetic project of César Vallejo, which begins to take shape from his first verses, contains -in addition to Quechua terminology and imaginary- records of orality and numerous identity elements typical of the Inca worldview in whose ancestry he took pride. The communal conceptions of the Inca Ayllu are found in his syncretic Christianity in The Black Messengers, and then manifest in Trilce, in frank opposition to the modern city's
\end{abstract}


hostility and contractual or mercantilist relations. This work aims to identify and study this persistent cultural identity from different entrances to his poetic work.

KEYWORDS: Ayllu, poetry, community, language, orality

\section{A marca andina na poesia de César Vallejo}

\section{Resumo}

Se em Los heraldos negros a rebelião temática se manifesta num mundo abandonado por Deus, e se em Trilce a rebelião categórica predomina contra o estatuto da língua e do universo simbólico, nas obras Poemas Humanos e España, aparta de mí este cáliz são a síntese perfeita de críticas sociais e humanas combinadas às mais ousadas transgressões formais. O projeto poético de César Vallejo, que começa a tomar forma após seus primeiros versos, contém - além da terminologia e o imaginário quíchua registros de oralidade e numerosos elementos de identidade típicos da cosmovisão inca de cuja ancestralidade ele se orgulha. As concepções comunais dos Ayllu Inca são encontradas em seu cristianismo sincrético nos Los heraldos negros e depois em Trilce, em franca oposição à hostilidade e às relações contratuais ou mercantilistas da cidade moderna. Este trabalho alveja identificar e estudar essa identidade cultural persistente nas diferentes entradas de sua obra poética.

PALAVRAS CHAVE: Ayllu, poesia, comunidade, linguagem, oralidade

La cuestión del indio, más que pedagógica, es económica, es social. Manuel González Prada, "Nuestros indios"

\section{El origen}

Este año se cumple un centenario de la publicación de Los heraldos negros. ${ }^{1}$ Fue tan descomunal la ruptura que produjo Trilce (1922) que durante mucho tiempo no se percibió el carácter innovador del primer poemario de César Vallejo. Sin embargo, como si en el propio título se cifrara un vaticinio, aquellos heraldos anuncian, anticipan una de las estéticas más singulares a pesar de las reminiscencias románticas o modernistas -incluso con ellas Vallejo hace otra cosa-: en este libro de juventud se inaugura un estilo, una matriz enunciativa junto con la tensión comunidad serrana (andina y solidaria) versus ciudad moderna (regida por las leyes del Capitalismo), tensión que se mantiene, con diferentes matices, en su producción posterior. Gran parte de su especificidad -si no toda- proviene de ese elemento identitario peruano, que Mariátegui llamó "la nota india" en Vallejo, y que nunca es color local estereotipado ni artificio folklórico, sino un "producto espontáneo" como también lo es su nostalgia autóctona -fiel componente indígena, según Valcárcel- que no viene del pesimismo nietzschiano sino de la experiencia histórica y "la actitud espiritual de una raza, de un pueblo" (Mariátegui, 2007: 260-263).

También se abusó de la exégesis cristiana, pero el imaginario religioso en esta poesía adopta formas sincréticas o se expresa de forma heterodoxa antes que manifestación devota o acatamiento gregario. Este aspecto también se vincula con las

1 Vallejo, César, Poesía completa, Ed. de Ricardo González Vigil, Lima, Ediciones Copé, 2013. Todas las referencias responden a esta edición y se cita con el número de página entre paréntesis en el texto. 
raíces culturales del peruano, en tanto se trata de una divinidad configurada con las debilidades y restricciones de los hombres: además de conocerlo muy bien, Vallejo posee la saludable distancia crítica respecto del culto como para poder percibir sus incongruencias. Comencemos por el poema homónimo:

Hay golpes en la vida, tan fuertes... Yo no sé!

Golpes como del odio de Dios; como si ante ellos,

la resaca de todo lo sufrido

se empozara en el alma... Yo no sé! (91)

El "yo no sé" con que se abre y cierra el poema no pareciera expresar tanto la incertidumbre metafísica como una forma de saber humilde, de tono bajo: la expresión coloquial del hombre común frente a algo que resulta inadmisible, su impotencia ante lo irreparable. Octavio Paz hace hincapié en la importancia de ese cambio de actitud poética que induce una estética de lo sencillo, de lo cotidiano y, sobre todo, en "el gran descubrimiento: los poderes secretos del lenguaje coloquial" ( $\mathrm{Paz}, 1990$ : 138139). En estas poéticas de transición la convivencia de terminologías y giros propios de la estética anterior con la irrupción de registros coloquiales y populares provoca, muchas veces, un mayor efecto de ruptura que si se tratase de un texto netamente vanguardista. En cuanto al "no sé", introduce una vulnerable y cálida sencillez, propia de la oralidad, acerca de un tema metafísico muy codificado por la poesía romántica y modernista. ${ }^{2}$ Vayamos a la tercera estrofa:

Son las caídas hondas de los Cristos del alma, de alguna fe adorable que el Destino blasfema.

Esos golpes sangrientos son las crepitaciones

de algún pan que en la puerta del horno se nos quema.

Tengamos en cuenta que los dos últimos versos fueron cambiados de una primera versión (1917): "Son esos rudos golpes las explosiones súbitas / de alguna almohada de oro que funde un sol maligno". A la hora de expresar la impotencia ante lo inexorable es clara la ganancia de la sustitución de "almohada de oro" y "sol maligno" -figuras rebuscadas, de resonancias modernistas- por la imagen mundana del pan que se quema en la puerta del horno (jtan cerca de lograrlo!). Alimento primordial, propio de todos: el pan compartido en comunidad -de ahí la identificación con la eucaristía-, que nutre y a la vez hermana. Porque no se trata del pan comprado en la panadería sino del que se amasa y cuece en el horno de la casa materna, y esta es una experiencia que remite a las pequeñas poblaciones antes que a las grandes ciudades. Ese pan emblemático, sagrado por social -que en Vallejo posee un aroma nostálgico a la herencia del Ayllu incaico-es el que se malogra, se descuida, se pierde por esos "golpes como del odio de Dios". Por otra parte, no solo estamos ante el "odio de Dios", sino que quienes lo sufren son, justamente, los "pobres" hombres, esos "Cristos del alma". El sujeto poético tiene un abrazo fraterno para el Cristo doliente a la vez que toma distancia del Padre todopoderoso; y a nadie puede escapársele que responsabilizar al odio de Dios de los tormentos de su hijo es una severa contravención al relato teológico tradicional.

"Huaco" (147) acaso sea el poema con mayor impronta andina de la sección "Nostalgias imperiales"; en él hay referencias a las cosmovisiones prehispánicas y en particular al mito de Inkarri. Según André Coyné, con este poema Vallejo ofrece un blasón poético (a la manera de los modernistas), un manifiesto en el que

2 Blanchot (1994: 142-143) dice que el "no sé" es sosegado y silencioso, que es una forma de saber que toma su atractivo del habla más simple; lo opone al "Sé”, marca soberana del saber intemporal que se apoya en un "Yo" autoritario: la afirmación de un saber que se quiere imponer como saber. 
proclama su filiación indígena, identificándose con los animales sagrados que los antiguos alfareros peruanos representaban en sus huacos (Coyné, 1957: 31).

La palabra huaco viene de la voz quechua waca que refiere a lo sagrado; es el nombre de un recipiente de cerámica para contener líquidos de todo tipo que los hallazgos arqueológicos vinculan a los ritos funerarios y cuyo uso se remonta a las primeras civilizaciones del Perú -son célebres por sus formas y motivos los de la cultura Nazca, Mochica y Chimú- pero a pesar de lo extendido del término su nominación original solo se aplicaba a los utilizados en las ceremonias religiosas. "Yo soy el corequenque ciego / que mira por la lente de una llaga": afirma en los primeros versos. Corequenque: nombre quechua de un ave de los Andes, cuyo vistoso plumaje era utilizado en el ornamento del inca. Ceguera y llaga son condiciones simbólicas que remiten al dolor y la mutilación de la cultura originaria. El sujeto poético claramente está reivindicando el componente indígena de su identidad mestiza. En la segunda estrofa la identificación recae en otro símbolo andino, la llama, fundamental en la economía incaica por su lana, su carne y como animal de carga, y nuevamente allí aparecen señales de agresión (la llama es trasquilada por "la necedad hostil"), mientras que el "asco" podría estar aludiendo al aculturamiento de quienes han resignado sus valores y costumbres por los brillos ilusorios del conquistador. Por su parte, la mención del "yaraví", además de la nota melancólica, por tratarse de una composición sincrética-canto que une elementos musicales aborígenes con formas de la poesía trovadoresca españolainstala el mestizaje, la mezcla inevitable que asegura la supervivencia del legado. ${ }^{3}$

En la estrofa siguiente la simbología es más directa: "soy el pichón de cóndor desplumado / por latino arcabuz" se refiere a la aniquilación por las armas de fuego del conquistador español. El sujeto poético asume la derrota de una civilización, la agonía de una cultura que se niega a desaparecer. Lo interesante allí es la persistencia de ese flotar sobre los Andes comparado con un "Lázaro de luz" (148). La resurrección resulta aludida por dos vertientes: el mito de Inkarri (que predice el retorno del Tawantisuyo desmembrado) y el evangelio cristiano. Pero esta conjunción, esta amalgama que se repite "en áureos coricanchas bautizados" no es inocua sino tensa, conflictiva: el templo inca consagrado al sol resulta "bautizado", es decir, profanado y trocado su culto por la creencia foránea (sobre el Coricancha del Cuzco los españoles construyeron la iglesia de Santo Domingo). Por otra parte, la pluralidad identitaria (corequenque, llama, pichón de cóndor y ahora "gracia incaica") nos habla de un sujeto poético que no remite a un individuo sino que asume la voz plural de una comunidad. Todo el poema está atravesado por esta tensión soterrada como esos "nervios rotos de un extinto puma", otro símbolo incaico. ${ }^{4}$

En los dos últimos versos el sujeto poético se afirma en "Un fermento de Sol; / ¡levadura de sombra y corazón!”. Euforia y esperanza: fermento, levadura, con estos elementos activos que producen cambios se anuncia un nuevo comienzo. El "Sol" con mayúsculas remite a la deidad inca y opuesto a "sombra" retoma el ciclo natural del día y la noche, de nacimiento y muerte, y la vida palpitando en el "corazón" de un cierre enfático que adquiere tono de apertura.

\footnotetext{
3 Más allá del nítido contraste entre "blasones", sugerido por Coyné, si cotejáramos el "Yo soy..." de este poema de juventud con el "Yo soy aquél...” de Cantos de vida y esperanza -especie de balance estético y vital de la madurez de Rubén Darío- podríamos ver que en el nicaragüense lo conflictivo parece estar en la propia identidad, en tanto reivindica un linaje, una tradición francesa -aunque sea literaria-, en cambio en Vallejo el conflicto se plantea frente a la conquista europea a partir de haber asumido su identidad andina, americana.

4 En cuanto a la organización y explotación económica del espacio geográfico, el Tawantisuyo fue la consolidación de un prolongado proceso previo, como lo explica el historiador y antropólogo Heraclio Bonilla, cuya eficacia reside en gran parte en las comunidades indígenas o Ayllus que responden a una concepción ampliada de lo familiar. En estos fundamentos de la cultura originaria reside también la fortaleza del campesinado de la región que, tanto en Bolivia como en Perú, logró imponer "reformas agrarias profundas, traducidas en la cancelación de los latifundios tradicionales" hacia mediados del siglo XX (Bonilla, 2008: 101-125).
} 
Todos los poemas de esta sección abundan en peruanismos y quechuismos e idealizan el mundo andino a la vez que asumen la perspectiva indígena, pero siempre desde la mezcla sincrética, transculturadora, donde la quena o el yaraví conviven con las bucólicas de Virgilio. El final de "Aldeana" (154) abre la retrospección melancólica del poema siguiente, "Idilio muerto" (155), en la que el Yo poético se pregunta qué estará haciendo su "andina y dulce Rita", la amada perdida a quien se describe como una muchacha que encarna el candor y la pureza femeninas pero a la vez contradice el estereotipo occidental. Es de piel cobriza "de junco y capulí" (capulli, nombre náhuatl de una planta tropical de frutos oscuros como las guindas), hacendosa en "sus afanes": una sencilla plebeya de "falda de franela" que plancha y cuando siente frío emplea exclamaciones religiosas. Esa imagen de dulzura y paz sencilla se opone tajantemente a la ciudad ruidosa y asfixiante, en la que ahora reside el sujeto poético, nombrada como "Bizancio", paradigmática metrópolis occidental, sinónimo de vicios, violencia y tentaciones de toda índole.

Parte de la crítica ha percibido una "irresuelta contradicción" en esta añoranza del espacio rural en oposición a la ciudad moderna, al punto de calificar la propuesta de "Idilio muerto" poco menos que de "esquizofrénica" ya que su "escritura, como signo de modernidad, no hace otra cosa que poner de relieve los valores naturales -y arcaicos- que habrían quedado oscuros y silenciados, en última instancia ágrafos, si no se los hubiera abandonado para ingresar en la modernidad" (Cornejo-Polar, 2003: 161-163). No estamos de acuerdo. A nuestro entender la contradicción se encuentra en el sistema político, económico y social que percibe el Yo poético en la gran ciudad respecto de ciertas zonas rurales donde todavía -al menos en el momento de la enunciación-se resguardan ciertos valores autóctonos y no en el poema que, en todo caso, pone en evidencia esa contradicción.

Respecto de lo "arcaico", como claramente lo explica Ángel Rama, el impacto modernizador en América Latina obligó a encontrar soluciones intermedias en las expresiones culturales originarias que, de haberse acantonado en posturas rígidas, habrían desaparecido. Es cierto que la lengua impuesta funcionó como instrumento de dominación de los conquistadores, pero tanto en la narrativa arguediana como en la poesía de Vallejo, el castellano se encuentra cribado, atravesado, desbordado por marcas orales, ritmos y concepciones de la civilización quechua: aunque se utilizaran el lenguaje escrito y las herramientas expresivas de la modernidad occidental, aquellos valores todavía se reconocían pertenecientes a la tradición propia y pudieron sobrevivir en la mezcla sincrética o transculturadora (Rama, 1987:32-44). Por otra parte, si Arguedas o Vallejo hubieran empleado el quechua como medio expresivo excluyente es obvio que sus obras no habrían tenido la difusión y trascendencia que tuvieron. Además, esta impronta nativa, estos ideologemas vernáculos junto a los efectos de la oralidad trasfundida a la escritura castellana son, en gran medida, los fundamentos de la singularidad de sus estéticas.

El proceso denominado transculturación que Rama toma del antropólogo cubano Fernando Ortiz, describe una respuesta dialéctica a las contradicciones y conflictos planteados en el seno de una cultura heterogénea-cuyas posibilidades expresivas se encuentran signadas por la asimetría y desigualdad-, lo cual no quiere decir que el producto de la neoculturación resuelva u homogenice esos problemas y tensiones. Por ello, entendemos con Raúl Bueno que los conceptos de transculturación y de heterogeneidad no se oponen sino que son complementarios, en tanto la transculturación designa y describe un tipo de dinámica dentro de la situación heterogénea de nuestro continente (Bueno, 1996: 21-36).

Volviendo a Los heraldos... hay, en este primer libro, muchas manifestaciones de la indignación frente a las miserias y carencias de los hombres que prevalecerán en su 
poesía posterior. Para ejemplo, veremos "La cena miserable" (175). El poema comienza con una formulación aparentemente contradictoria: "Hasta cuándo estaremos esperando lo que / no se nos debe...". Si bien podría interpretarse literalmente como estar esperando algo que no nos corresponde, el tono y las imágenes que siguen (la cruz, el padecimiento, un niño que no puede dormir por el hambre y el cuestionamiento que no cesa: " ¿hasta cuándo este valle de lágrimas" de los pobres?) hacen pensar que si se tratara de una frase racional, lineal, la interpelación debiera decir "hasta cuándo estaremos esperando lo que se nos debe" por el solo derecho de existir y ser humanos. ¿Por qué entonces escribe "lo que no se nos debe", es decir, lo contrario? Una posible explicación sería que el atajo poético incorpora con ese "no" la negación del sistema, la mezquindad implícita en la estructura de avasallamiento y explotación que nunca va a reconocer esa deuda. En esa formulación, entonces, habría dos voces, la del sujeto poético plural, que habla por los hambrientos y desvalidos, y la ley implacable de la mayor ganancia a cualquier costo.

De ahí que el cierre sea pesimista y desolador al concluir con ese oscuro horizonte en que aguarda, burlona, "la tumba" como única liberación de ese "valle de lágrimas" (176). Pero ese pesimismo, ese repetido "hasta cuándo" debería ser leído como un llamado de atención acerca de la inutilidad de la espera pasiva, sobre todo si tenemos en cuenta la irreverencia del sujeto poético en el trato con Dios. Lejos de resignarse con la promesa de un más allá venturoso o compensatorio, ese pesimismo iterativo acumula el hartazgo como preámbulo de la insumisión.

En "Absoluta" (169) se refuerza el reclamo por la pasividad o la impotencia del Creador: "Mas, ¿no puedes, Señor, contra la muerte, contra el límite, contra lo que acaba?". Y en "Los dados eternos" (183) aún va más lejos al ubicarlo por debajo del hombre. Mientras que el Cristo es santificado en la acción comunitaria, resulta cuestionado el Dios católico, instrumental, del conquistador. Pero no hay soberbia ni rencor en su cuestionamiento, sino humilde nostalgia, tristeza colectiva. En Vallejo el dolor siempre posee un trasfondo universal -como ya lo señalara Antenor Orrego-, rasgo que también remite a la cultura indígena, a ese animismo íntimo, "genuino y esencial", donde "la palabra quechua, el giro vernáculo no se injertan artificiosamente en su lenguaje, [sino que] son el producto espontáneo, célula propia, elemento orgánico" (Mariátegui, 2007: 260).

\section{El alquiler del mundo}

Hasta aquí algunos ejemplos de Los heraldos negros; veamos qué sucede en un poema emblemático de Trilce, el XXIII: "Tahona estuosa de aquellos mis bizcochos / pura yema infantil innumerable, madre" (257), donde el adjetivo que denota abundancia se extiende a la madre cocinera, proveedora, multiplicada en el recuerdo, mientras que toda la escena remite a la comunión: al trasmutarse aquellos "bizcochos" en ofrendas sagradas se connota la eucaristía pero en clave sincrética. La retrospección nos muestra la prodigalidad de la vivencia familiar, la época del don, de la entrega, del repartir y compartir aquellas "ricas hostias" -y aquí la acepción al sabor también alude a la abundancia de un patrimonio afectivo, espiritual. En cambio, el contraste con el mundo del presente del enunciado no podría ser mayor: ahora, con la madre muerta y lejos de la casa familiar, lejos de la comunidad rural de la serranía, inmerso en el mercantilismo de la ciudad cosmopolita y hostil (Lima), el yo lírico se enfrenta a la orfandad de una existencia mezquina donde no se regala nada, donde "nos van cobrando todos / el alquiler del mundo donde nos dejas / y el valor de aquel pan inacabable".

En este "execrable sistema"-como lo califica en "Por último, sin ese buen aroma sucesivo..." (439) de Poemas humanos- donde rige la explotación del hombre por el hombre, 
la "riqueza" ya no alude al sabor ni al afecto ni a la comunión espiritual sino a la mayor ganancia que acumulan unos pocos en detrimento de esa mayoría desposeída que debe pagar el alquiler del mundo, el costo de la existencia. Aquí la trascendencia del sentido parece residir en la forma en que se opone el "alquiler"-o sea el precio-con el valor. Porque es evidente que las adjetivaciones "innumerable" como "inacabable" apelan a lo simbólico, a un legado que no tiene precio y por lo tanto no puede comprarse ni ser reducido a mercancía. Coincidimos con Enrique Foffani cuando interpreta que en los poemas de la saga familiar, y este en particular, la oposición al sistema capitalista se manifiesta en el contraste con la comunidad andina, con "ese ayllu familiar que es un espacio de indudable transculturación" (Foffani, 2018: 112).

Por otro lado, tenemos las alusiones a la prisión (III; XVIII; L; LVIII) que no son precisamente metáforas dado que, efectivamente, Vallejo escribió muchos de estos poemas mientras cumplía una condena en el presidio de Trujillo -acusado injustamente de haber participado del saqueo e incendio de la casa de unos comerciantes-, entre 1920 y 1921. Veamos un fragmento del XVIII: "Oh las cuatro paredes de la celda. / Ah las cuatro paredes albicantes / que sin remedio dan al mismo número. [...] Amorosa llavera de innumerables llaves, / si estuvieras aquí, si vieras hasta / qué hora son cuatro estas paredes. / Contra ellas seríamos contigo, los dos, / más dos que nunca. Y ni lloraras, / di, libertadora!". La multiplicación del tiempo por el encierro aparece cifrada en la repetición de "las cuatro paredes", mientras el deseo se atreve a soñar y asomarse en el juego numérico con el "dos" del amor ("más dos que nunca"), de la liberación. Al igual que en el XXIII, lo inconmensurable aparece asociado al ser (y al hacer) materno -recordemos que en las comunidades originarias la mujer era el centro, la madre antes que el padre, como sucede en esta poesía-, y otra vez la invocación de la ausente ("¿di, mamá?") clausura el poema a la vez que su condición de libertaria contrasta con el presente de la cárcel.

Cuando Vallejo se identifica con las técnicas vanguardistas de los cineastas rusos como lo señala Matías Di Benedetto a propósito de algunos pasajes de Contra el secreto profesional-, y en particular con el principio constructivista que proponía el cineasta Dziga Vertov ("Cine-Verdad"), es porque ya operaba con este concepto organizativo y articulador del sentido de los materiales (Di Benedetto, 2018: 126-130). Y esto puede percibirse aun en aquellas composiciones de mayor audacia formal, en las que prevalece la transgresión lingüística, como en Trilce IX. Allí la carga semántica se apoya en el desvío de la norma: en los versos que repiten el encabezamiento de las tres estrofas primeras (Vusco volvvver de golpe el golpe...) en cuya sucesión iterativa el énfasis de la acumulación de la v corta (fricativa) resultará mermado por la sustitución por la b larga (bilabial) para significar el pasaje de la euforia a la declinación del deseo, hasta que el verbo "buscar" se trueca por "fallar" y el verbo volver se ablanda con la inoportuna bilabial (Fallo bolver de golpe el golpe...). La estructura del poema obedece a un eje o idea organizadora, incluso utilizando las alteraciones de los significantes, la infracción gramatical y el recurso iterativo con sus variantes.

Otro poema ejemplar, tomado de Poemas humanos, posee estrofas de cinco versos; cuatro endecasílabos en los que se inserta siempre el mismo heptasílabo, "la cólera del pobre", lo cual genera un corte de efecto rítmico singular: "La cólera que quiebra al hombre en niños, / que quiebra al niño en pájaros iguales, / y el pájaro, después, en huevecillos; / la cólera del pobre / tiene un aceite contra dos vinagres". En el último endecasílabo de cada estrofa también se repite la disposición: "tiene [estructura 1] contra [estructura 2]", pero además ambos sintagmas opuestos pertenecen a un mismo rango semántico (aceite-vinagre; acero-puñal; río-mar; fuego central-cráter): la confrontación se establece en el seno de una familiaridad significativa. Ahora bien, así como el retroceso y la deshumanización residen en la violencia de una sociedad asimétrica que "quiebra al hombre en niños", al niño en pájaros, y al pájaro reduce 
hasta sus huevos -como en una secuencia de involución-, el sentido de desigualdad se encuentra expresado por el modificador numérico de la estructura-propiedad de "la cólera del pobre" que, coherentemente, siempre está en desventaja, uno contra dos o dos contra muchos: 1) "la cólera del pobre / tiene un aceite contra dos vinagres." 2) "la cólera del pobre / tiene dos ríos contra muchos mares." 3) "la cólera del pobre / tiene un acero contra dos puñales".

El poeta peruano nunca, pero nunca, reniega de su origen. Es más, en París se le conoce como "el Cholo Vallejo", él mismo se nombra así en su elegía al amigo muerto, Alfonso de Silva: "Palpablemente, / tu inolvidable cholo te oye andar / en París, te siente en el teléfono callar..." (520). Como anota Foffani, cuanto más afuera estaba físicamente del Perú, más adentro de sus valores andinos se manifestaba su poesía (2018: 249). Ahora vamos a saltearnos lo obvio de sus versos dolientes por la patria lejana, la marca en una piedra ("diecisiete") perdida en el recuerdo. Recuerdo de los cerros "pintados de creencias", recuerdo del domingo peruano desde un presente en que las semanas pesan como siglos en la tristeza de la insalubre Europa (su tos y su miseria sin respiro, sus carencias sin pausa, todo siempre "clavado en pleno pecho", iterativo). Nos salteamos, también, la evidente nostalgia de "Fue domingo en las claras orejas de mi burro, / de mi burro peruano en el Perú..." (441), así como la exultante "Telúrica y magnética” (455): “¡Mecánica sincera y peruanísima...!", donde canta a la cordillera, al molle y a la coca, al picante rocoto, al surco inteligente del cultivo en terrazas, al cuy y la antigua técnica del agua: "iIndio después del hombre y antes de él!" (457).

Sí, nos salteamos lo que exhibe con orgulloso énfasis porque eso es notorio; quisiéramos concluir con la matriz andina, la del resorte oculto, la que mueve los hilos, las ideas, las palabras que sueldan sus poemas. Porque gran parte de su radical experimentación con el lenguaje -algo que toda la crítica le reconoce- entendemos que proviene de su arraigado andinismo, de su intento de transferir a la escritura énfasis y giros propios de la oralidad, de ahí también que nunca comulgara con el léxico tecnológico y superficial de la vanguardia, sobre todo de cierta "poesía nueva" que iba prendida a la cola del Futurismo de Marinetti. ${ }^{5}$

Alberto Escobar-entre otros- analizando algunos de los Poemas humanos, ha señalado que esta exploración estilística abunda en recursos -enfáticos, iterativos, rítmicosdirigidos a incorporar el habla natural al discurso poético y que esta experimentación obedecía a la búsqueda de convertir el lenguaje "en un filtro dialéctico de la realidad total" (Escobar, 1973: 224).

\section{Coda}

Hay algo tan entrañable, tan expansivo, enfático y auténtico en Vallejo, que no se termina nunca de asir, de aprehender. Es algo tierno y duro a la vez, tal vez sea hueso, su esqueleto poético: esa convicción vigorosa que asoma en la sublevación contra la regla gramatical, la que rescata la falta y la esgrime como proclama urgente de carencia, de cara al viento: "VViban los compañeros! Pedro Rojas" (611). Como dice Cornejo-Polar (2003: 218-222), estos desvíos ortográficos y desbordes expresivos, en que la escritura se articula con la voz oral y se comportan "como si la carga dramática

\footnotetext{
5 Aunque Vallejo se refirió en varias ocasiones al carácter frívolo y superficial de cierta poesía que se pretendía "moderna" sólo por incorporar términos nuevos, tomaremos como ejemplo su artículo "Poesía nueva" -publicado en la revista Amauta, en 1926- donde sostiene que no se trata de reproducir nombres o palabras vinculadas a la tecnología o los inventos de la modernidad sino de asimilar los materiales que ofrece la vida moderna para producir una nueva sensibilidad (Schwartz 478-479).
} 
del poema no pudiera caber en el espacio cerrado de la escritura", provienen de la cultura popular en la que prevalece la palabra hablada y escuchada.

Totalmente de acuerdo: de allí viene esa fuerza insurgente, esa matriz contestataria. Matriz desde el terruño que le enseñara otra manera de mirar, de medir, de ser y de ponerse del lado de "la cólera del pobre" aunque eso implicara quedar en desventaja o justamente por eso. Matriz de la que emergen versos con el hollín portentoso de los mineros peruanos pero también con la integridad del campesino que "habla como le vienen las palabras", restringidas, escasas, "colgando de otro palo", del que se lavará "la cara acariciándose con sólidas palomas" (460). Es la impronta, la sensible matriz de una cultura otra que le permite encontrar el peso específico de los hombres humanos y de sus actos: devolver su aura a esas manos fuertes y pacíficas que, agrandadas por el trabajo rural, encuentran su franca analogía en la figura alada; bajarlo del madero al Cristo, resucitar al verbo, al combatiente, para que vuelva a escribir "con el dedo grande en el aire". Como ninguna, la poesía de Vallejo coloca al hombre hacedor y proletario por encima de todo, porque como dice en España...: "Todo acto o voz genial viene del pueblo" (600), y esta afirmación está implícita desde sus primeros poemas, desde aquellos escritos al amparo de los valores solidarios de la comunidad andina. 


\section{Dibliografía}

» Blanchot, M. (1994). El paso (no) más allá. Barcelona: Paidós.

"Bonilla, H. (2008, junio). “Los Andes: la metamorfosis y los particularismos de una región”. Crítica y Emancipación, Revista latinoamericana de Ciencias Sociales, Año 1, $N^{\circ}$ 1, Buenos Aires, CLACSO, pp. 101-125.

»Bueno, R. (1996). "Sobre la heterogeneidad literaria y cultural en América Latina". En Asedios a la heterogeneidad cultural. Libro de homenaje a Antonio Cornejo Polar (José Antonio Mazzotti, U. Juan Zevallos, Aguilar Eds.). Lima: Asociación Internacional de Peruanistas.

»Cornejo-Polar, A. (2003). Escribir en el aire. Lima: Latinoamericana Editores.

»Coyné, A. (1957). César Vallejo y su obra poética. Lima: Letras Peruanas.

»Di Benedetto, M. (2018). “Estéticas del montaje. Representaciones de lo andino en la narrativa de vanguardia peruana de los veinte" (Tesis doctoral aún inédita). Universidad Nacional de La Plata.

»Escobar, A. (1973). Como leer a Vallejo. Lima: Villanueva Editor.

» Foffani, E. (2018). Vallejo y el dinero. Formas de la subjetividad en la poesía. Lima: Editorial Cátedra Vallejo.

»Mariátegui, J. C. (2007). 7 ensayos de interpretación de la realidad peruana (3르. Ed.). Caracas: Biblioteca Ayacucho.

» Rama, Á. (1987). Transculturación narrativa en América Latina. México, Siglo XXI.

»Paz, O. (1990). Los hijos del limo. Barcelona: Seix Barral.

»Schwartz, J. (2002). Las vanguardias latinoamericanas. México: FCE.

»Vallejo, C. (2013). Poesía completa (Ed. de R. González Vigil). Lima: Ediciones Copé.

»Vallejo, C. (2002). "Poesía nueva”. En Schwartz, J., Las vanguardias latinoamericanas. México: FCE, pp. 478-479. 